\title{
Celery Seed Oil
}

National Cancer Institute

\section{Source}

National Cancer Institute. Celery Seed Oil. NCI Thesaurus. Code C73524.

The oil extracted from the seeds of Apium graveolens. Celery seed oil is used to treat disorders of the digestive system. 